University for Business and Technology in Kosovo

UBT Knowledge Center

UBT International Conference

2015 UBT International Conference

Nov 7th, 9:00 AM - 5:00 PM

\title{
Noise reduction in Quadcopter Accelerometer and Gyroscope Measurements based on Kalman filter
}

\author{
Bertan Karahoda \\ University for Business and Technology, bkarahoda@ubt-uni.net \\ Xhemajl Mehmeti \\ University for Business and Technology, xhemajl.mehmeti@ubt-uni.net \\ Uran Cabra \\ University for Business and Technology, uqabra@gmail.com
}

Follow this and additional works at: https://knowledgecenter.ubt-uni.net/conference

Part of the Robotics Commons

\section{Recommended Citation}

Karahoda, Bertan; Mehmeti, Xhemajl; and Cabra, Uran, "Noise reduction in Quadcopter Accelerometer and Gyroscope Measurements based on Kalman filter" (2015). UBT International Conference. 42.

https://knowledgecenter.ubt-uni.net/conference/2015/all-events/42

This Event is brought to you for free and open access by the Publication and Journals at UBT Knowledge Center. It has been accepted for inclusion in UBT International Conference by an authorized administrator of UBT Knowledge Center. For more information, please contact knowledge.center@ubt-uni.net. 


\title{
Noise reduction in Quadcopter Accelerometer and Gyroscope Measurements based on Kalman filter
}

\author{
Bertan Karahoda ${ }^{1}$, Xhemajl Mehmeti ${ }^{2}$, Uran Cabra ${ }^{3}$ \\ ${ }^{1}$ UBT - Higher Education Institution \\ \{bkarahoda ${ }^{1}$, xhemajl.meh meti $\left.{ }^{2}\right\} @$ ubt-uni.net, uqabra@gmail.com ${ }^{3}$
}

\begin{abstract}
The Accelerometer and Gyroscope modules used for measuring the orientation of the quadcopter usually generate noisy signals which directly affect the control strategies. The high speed motors used in quadcopters cause high noise levels which makes the real time control almost impossible. In this work the Kalman filter is applied to the noisy measurements obtained from accelerometer and gyroscope modules. The measurements are conducted for two cases: Motors stopped, and Motors activated at high speed. The Kalman filtering is applied separately for each measurement and the obtained results show noticeable improvement in noise level for two cases. The joint implementation from accelerometer and gyroscope modules is also conducted in order to optimize the predicted signal levels. The results show that the proposed Kalman filtering method can be used in real time measurement of quadcopter orientation, also in the case of low-cost measurement modules.
\end{abstract}

Keywords: Kalman Filter, Noise Reduction, Quadcopter Sensor Modules, Noisy Accelerometer

\section{Introduction}

The quadcopters are widely used for different purposes. There are several control strategies and methods used for controlling the operation of quadcopters [1]. The gy roscope and accelerometers are main feedback sensors used in quadcopter control system. There are several low cost and high cost types of these sensors. Because of the high speed of the DC motors, the high level noise is present in sensor measurements. The hardware solutions to eliminate these noises are quite difficult as soon as the sensors cannot be totally isolated from quadcopter body, and there always will be vibrational effects on sensors. These vibrational effects will have higher impact on accelerometer measurements. There are high cost sensors that minimize the noise effects on sensor measurements, on the other hand there are several filtering techniques used to minimize the noise. In this work the low cost integrated accelerometer and gyroscope sensor module is used for eliminating the high level noise.

The Kalman filter is the optimal estimator and is widely used in noise reduction when the process and measurement noises are known [2,3]. The process noise is usually difficult to model when there is no access to the system parameters, such as in the case of sensor modules. Therefore the measurement noise can be modelled to obtain the state space model of the quadcopter for gyroscope and accelerometer measurements.

\section{Kalman Filter}

The state space model for any linear time invariant system can be given by equation (1) and (2):

$$
\begin{aligned}
& X_{k+1}=A X_{k}+B U_{k}+W_{k} \\
& Y_{k+1}=H X_{k}+V_{k}
\end{aligned}
$$

$\mathrm{X}$ is the system state, $\mathrm{U}$ is the input vector, $\mathrm{Y}$ is the system output, $\mathrm{A}$ is the state transition matrix, $\mathrm{B}$ is the process noise coupling matrix, $\mathrm{H}$ is the measurement sensitivity matrix and the $\mathrm{W}$ and $\mathrm{V}$ are measurement and process noises respectively $[4,5]$. When the system is modelled according to the 
equations (1) and (2) the Kalman filter gain $\mathrm{K}$ can be computed by using the propagation and measurement step equations.

Propagation Step:

$$
\begin{gathered}
\hat{x}_{k}^{-}=A \hat{x}_{k-1}+B u_{k} \\
P_{k}^{-}=A P_{k-1} A^{T}+Q
\end{gathered}
$$

Measurement Step:

$$
\begin{gathered}
K_{k}=P_{k}^{-} H^{T}\left(H P_{k}^{-} H^{T}+R\right)^{-1} \\
\hat{x}_{k}=\hat{x}_{k}^{-}+K_{k}\left(y_{k}-H \hat{x}_{k}^{-}\right) \\
P_{k}=\left(I-K_{k} H\right) P_{k}^{-}
\end{gathered}
$$

$\mathrm{K}$ is the Kalman gain, $\mathrm{P}$ is the covariance update and $\mathrm{R}$ and $\mathrm{Q}$ are measurement noise covariance and process noise covariance matrices respectively.

\section{Expe rimental Setup}

The quadcopter with high speed de motors and integrated sensor module is given in figure 1 . The Arduino mega microcontroller board is used for data collection and for control of the dc motors.

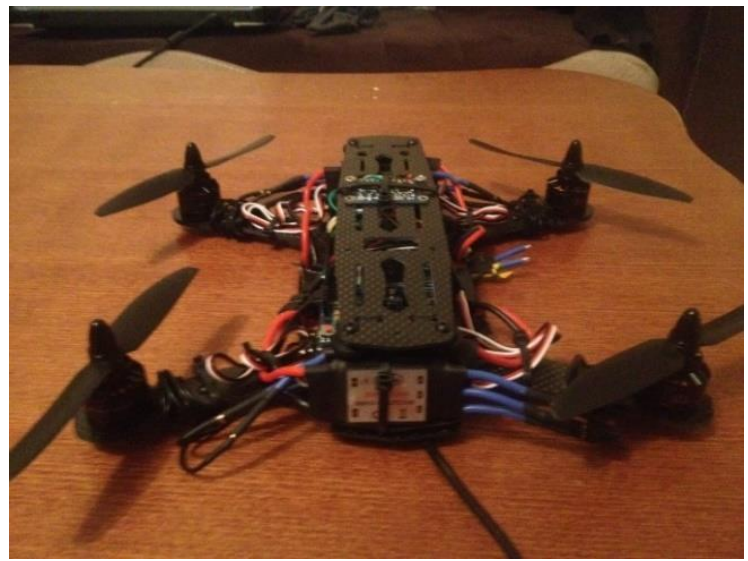

Figure 1 Quadcopter Structure

In quadcopter control system usually the raw and pitch angles are used as feedback to the controller. The measurements are made for raw and pitch angles by using the low cost integrated sensor module. The noisy measurements obtained for raw angle $(\mathrm{X})$ are shown in figure 2 for two cases: when motors are turned off and on. As can be seen from the obtained measurements for two cases, there are high level noise which makes it impossible to control the quadcopter by using this sensor module. 


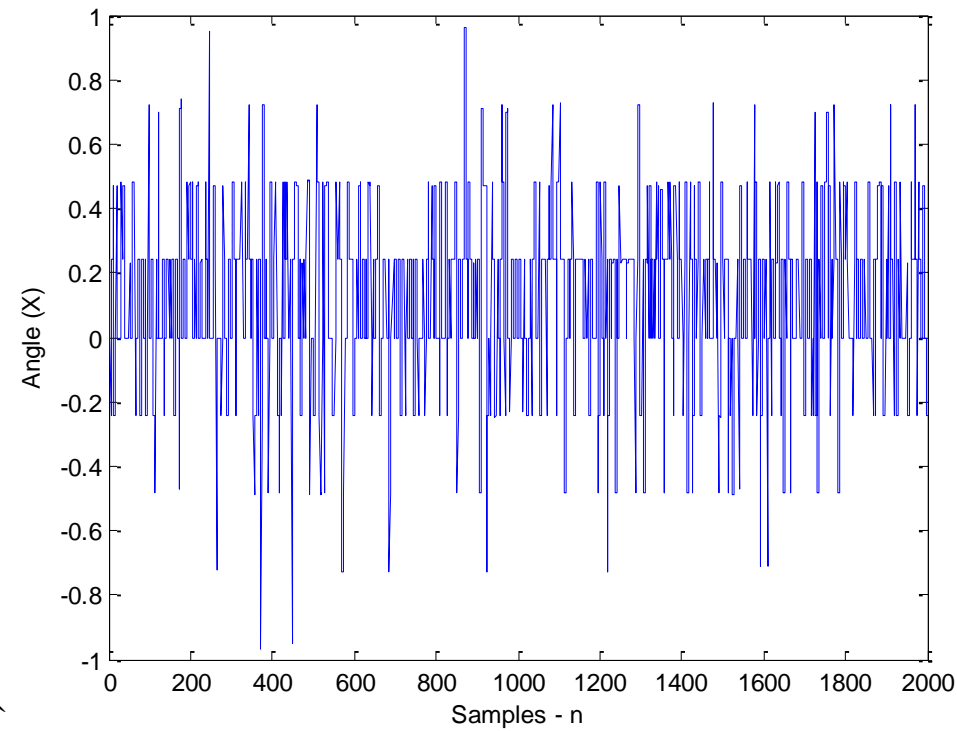

a)

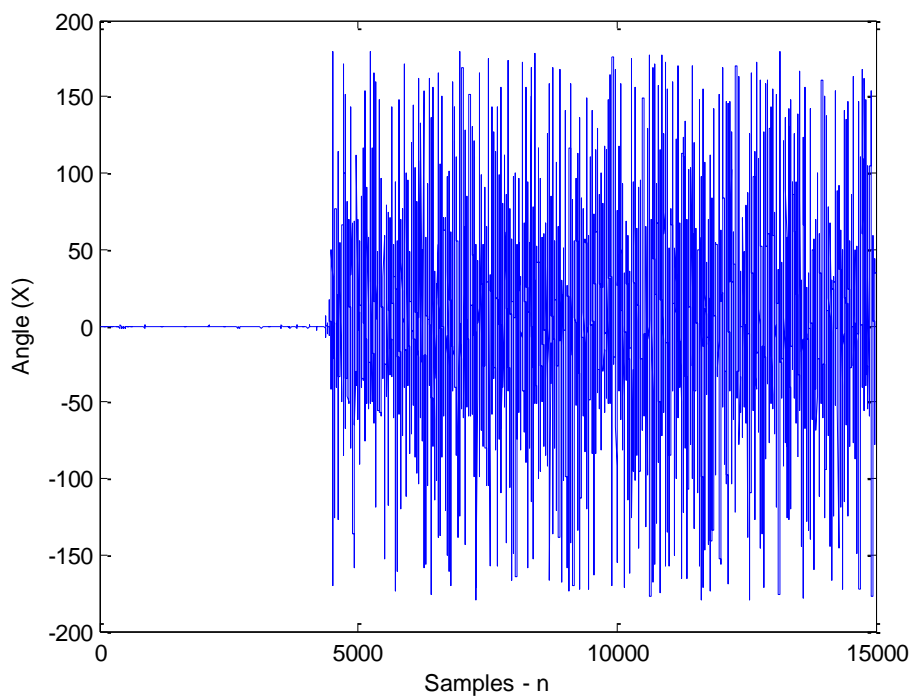

b)

Figure 2 Measurements for angle X, a) motors turned off, b) motors turned on

The process noise is usually difficult to model and process in case of sensor modules. Therefore the only measurement noise is modelled and obtained by time averaging the measured values. The state space, and propagation and measurement step equations for the proposed model are given below:

Where,

$$
\begin{gathered}
X_{k+1}=A X_{k}+W_{k} \\
Y_{k+1}=H X_{k}
\end{gathered}
$$

$$
\begin{gathered}
X=\left[\begin{array}{ll}
X_{\theta} & Y_{\theta}
\end{array}\right] \\
A=\left[\begin{array}{ll}
1 & 0 \\
0 & 1
\end{array}\right] \\
W=\left[\begin{array}{ll}
w_{x} & w_{y}
\end{array}\right] \\
H=\left[\begin{array}{ll}
1 & 0 \\
0 & 1
\end{array}\right]
\end{gathered}
$$




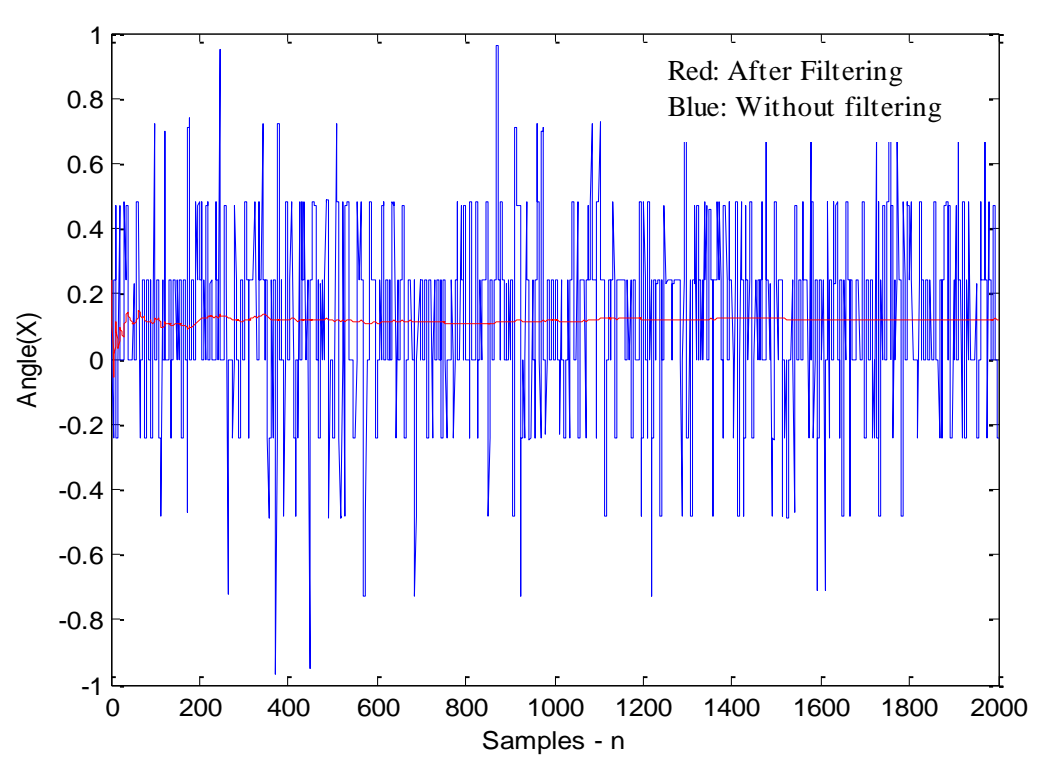

a)

The resulting propagation and measurement step equations are:

$$
\begin{gathered}
\hat{x}_{k+1}^{-}=A X_{k} \\
P_{k+1}^{-}=H X_{k} H^{T} \\
K_{k}=P_{k}^{-} H_{k}^{T}\left(H_{k} P_{k}^{-} H_{k}^{T}+R_{k}\right)^{-1} \\
\hat{x}_{k}=\hat{x}_{k}^{-}+K_{k}\left(y_{k}-H_{k} \hat{x}_{k}^{-}\right) \\
P_{k}=\left(I-K_{k} H_{k}\right) P_{k}^{-}
\end{gathered}
$$

\section{Results}

The Kalman filter equations are executed in an iterative process in order to eliminate the noise in sensor measurements. The filtering process is executed in Matlab and then is transferred to the microcontroller. The results are shown in figure 3. 


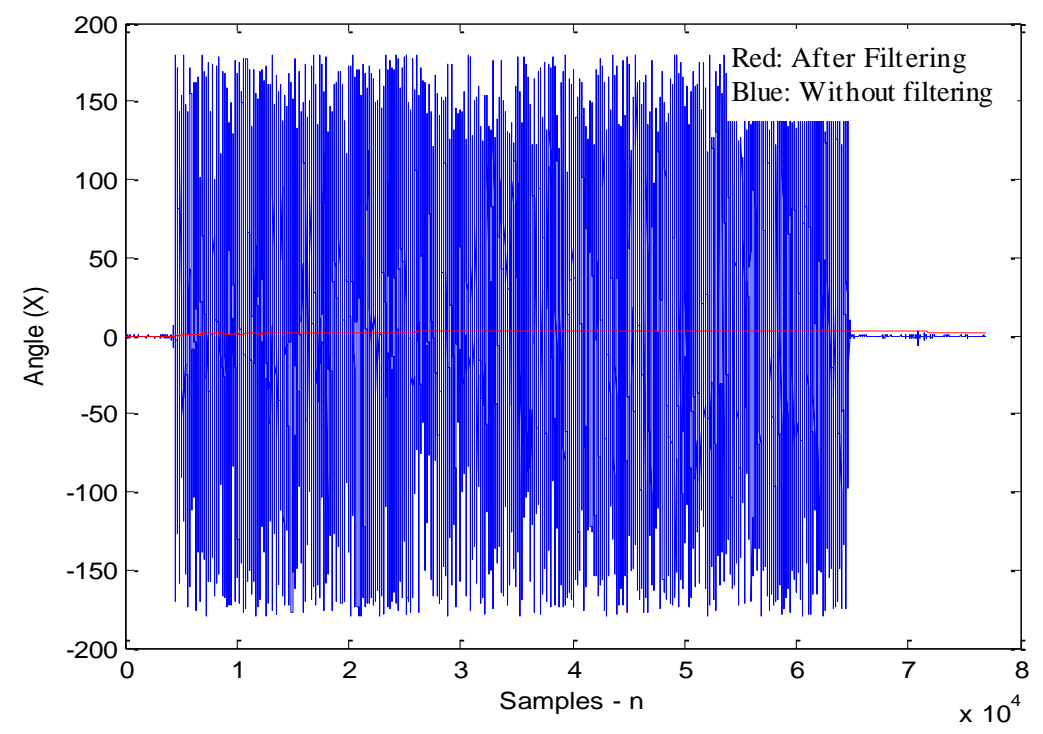

b)

Figure 3 The results of Kalman filtering, a) motors off, b) motors on

\section{Conclusion}

In quadcopter applications the sensors used for orientation calculation are usually sensitive to noise. The sensors cannot be totally isolated from quadcopter body and there will alway s be noise component which will make difficult to control the quadcopter. In case of low cost sensors these noises are higher and without filtering it is almost impossible to control the system.

In this work the Kalman filter is applied to the orientation measurements obtained from gy roscope and accelerometer integrated low cost sensor module. After Kalman filtering the noise level is reduced to the acceptable rate for gy roscope and accelerometer measurements. The few iterations are needed for Kalman filter to estimate the orientation values which makes it possible to apply the proposed model in real time control. The fusion of gyroscope and accelerometer results can be used to further increase the accuracy of the system.

\section{References}

1. F. R. R. Raúl M. Criado, "Autonomous path tracking control design for a comercial quadcopter," in 1st IFAC Workshop on Advanced Control and Navigation for Autonomous Aerospace Vehicles ACNAAV'15, Seville, Spain, 2015.

2. O. S. S.A.Quadri, "Error and Noise Analysis in an IMU using Kalman Filter," International Journal of Hybrid Information Technology, pp. 39-48, 2014.

3. C. Kownacki, "Optimization approach to adapt Kalman filters for the real-time application of accelerometer and gy roscope signals' filtering," Digital Signal Processing, pp. 131-140, 2011.

4. P. A. Mohinder S. Grewal, KALMAN FILTERING - Theory and Practice Using MATLAB, New Jersey: John Wiley \& Sons, Inc., 2015.

5. H. M. Paul Zarchan, Fundamentals of Kalman Filtering: A Practical Approach, USA: American Institute of Aeronautics and Astronautics, Inc., 2009. 